\title{
ANALISIS SISTEM PENGENDALIAN BANJIR SUNGAI PAMPANG DAERAH ALIRAN HULU SUNGAI KARANGMUMUS
}

\author{
Purwanto \\ Dosen Fakultas Teknik \\ Universitas 17 Agustus 1945 Samarinda \\ Email : Poerck69@gmail.com/HP.085250014524
}

\begin{abstract}
ABSTRAK
Tujuan dari penelitian adalah membuat analisis sistem pengendalian banjir, memberikan informasi tentang sistem pengendalian banjir dengan berbagai skenario yang direncanakan.Studi dilaksanakan selama 4 bulan pada Sub DAS Karangmumus hulu yang terletak di Kelurahan Sei Siring Kecamatan Samarinda Utara Kota Samarinda, Provinsi Kalimantan Timur. Secara garis besar ruang lingkup studi meliputi : (1) melakukan survey lapangan secara detail, (2) mengidentifikasi faktor-faktor yang menyebabkan banjir, dan (3) memberikan kontribusi yang nyata dari program pembangunan yang berwawasan lingkungan untuk meminimalkan dampak lingkungan dan sosial yang terjadi. Hasil studi menunjukkan bahwa : (1) penyebab permasalahan banjir secara alam yang paling dominan adalah kondisi topografi daerah rawan banjir yang relatif rendah dan datar dan merupakan daerah konsentrasi limpasan permukaan dari daerah tangkapan air sungai Karang Mumus dan Sungai Pampang, (2) sistem drainase masih menghadapi permasalahan baik itu secara sistem, sarana fisik/struktur maupun kendala yang bersifat non struktur, (3) berdasarkan kajian potensi pengendali banjir, sistem pengendalian banjir Sungai Karang Mumus Atas dapat dilakukan secara struktural maupun nonstruktural, dan (4) ada 5 buah skenario sistem pengendalian banjir yang ada. Dalam skenario tersebut dilakukan kombinasi antara kondisi eksisting dengan beberapa bendali dan sudetan. Sementara juga dilakukan skenario dengan hanya melakukan normalisasi sungai Pampang.
\end{abstract}

Kata Kunci : Sistem Pengendalian Banjir, DAS Sungai Pampang hulu Karang Mumus

\begin{abstract}
The purpose of the research is to make the analysis of flood control system, and provides information about flood control system with various scenarios planned. The research was conducted for about four months at the Upstream Karangmumus sub-watershed located in Sei Siring Urban-village of North Samarinda Sub District, Samarinda Municipality, East Kalimantan. Generally, the scope of the research include: (1) conduct a field survey in detail, (2) identify the factors that cause flooding, and (3) formulate recommendation for making a
\end{abstract}


JURNAL KACAPURI

JURNAL KEILMUAN TEKNIK SIPIL

Volume 3 Nomor 2 Edisi Desember 2020

significant contribution for the development program of environmentally sound to minimize the environmental and social impacts that could occur. The research results showed that: (1) the most dominant cause of the flooding problems naturally is the topographical conditions of flood prone areas which is relatively low and flat, and it is an area of concentration of surface runoff from the catchment area of the Karang Mumus river and Pampang river; (2) the drainage system is still face problems either in the system, physical facilities/ structures and non structure constraints; (3) based on the study of potential flood control, flood control systems at Upper zone of Karang Mumus River could be applied both structural and nonstructural mechanisms; and (4) there are five scenarios of existing flood control system. In such scenarios, the flood control system applied a combination of existing conditions with some bendali and diversion. Apart of that, the flood control system also applied the scenario with only normalizing the Pampang river.

\section{Keywords: Flood Control System,Sungai Pampang hulu Karang Mumus Watershed}

\section{PENDAHULUAN}

Kota Samarinda yang merupakan Ibukota Provinsi Kalimantan Timur tengah dilanda permasalahan yang cukup serius, yaitu permasalahan banjir. Akhir-akhir ini banjir sangat sering terjadi, sehingga sangat mengganggu aktifitas warganya. Berbagai upaya yang sudah dilakukan ternyata belum optimal dalam mengatasi masalah banjir tersebut.

Upaya yang telah dilakukan berupa pemeliharaan saluran drainase maupun sungai-sungai yang melintasi wilayah Kota Samarinda, berbagai studi dan pembangunan sarana pengendali banjir serta beberapa aturan telah dikeluarkan untuk pengendalian banjir, tetapi upaya tersebut kalah cepat dengan perkembangan kota. Oleh sebab itu diperlukan suatu penataan terpadu pengendalian banjir dengan menyusun prioritas dan pembiayaan sesuai dengan kondisi aktual serta prediksi perkembangannya.

Sebagian besar wilayah kota Samarinda yang bermasalah dengan banjir berlokasi di DAS Karangmumus $\left(320 \mathrm{~km}^{2}\right)$. Selain itu terdapat dua sub sistem lain yang juga mempunyai masalah banjir yaitu DAS Karang Asam Besar $\left(9,65 \mathrm{~km}^{2}\right)$ dan DAS Karang Asam Kecil $\left(16,25 \mathrm{~km}^{2}\right)$. Sedangkan untuk wilayah Samarinda Seberang daerah rawan banjir terletak di sekitar Loa Janan, sungai Rapak Dalam dan sungai Palaran.

Daerah rawan banjir DAS Karangmumus tersebar mulai dari daerah hulu, daerah tengah sampai dengan daerah hilir. Daerah rawan banjir DAS Karangmumus bagian hulu terletak di Kelurahan Sei Siring, tepatnya di daerah Pampang. Di daerah ini setiap tahun selalu dilanda banjir. Peristiwa banjir besar terakhir terjadi pada bulan April 2009 yang merendam wilayah Pampang sedalam 1 - 1,5 meter 
dengan lama genangan lebih dari 3 hari. Selama terjadi musibah banjir tersebut aktivitas sosial ekonomi masyarakat Pampang terhenti, karena akses jalan masuk dan keluar wilayah Pampang terputus. Kejadian banjir saat itu selain disebabkan oleh curah hujan yang tinggi juga terhambatnya aliran di sungai utama Karangmumus dan dua anak sungainya (Pampang Kiri dan Pampang Kanan). Kondisi saluran drainase di daerah rawan banjir Pampang yang masih belum tertata dengan baik juga memberi kontribusi terhadap permasalahan banjir yang terjadi.

Saat ini di daerah Karangmumus Hulu telah terjadi peningkatan pemanfaatan lahan dari lahan yang tidak produktif berupa semak menjadi lahan perkebunan, selain itu juga telah dimulainya pembangunan Bandara Samarinda Baru yang berlokasi di Kelurahan Sei Siring. Perubahan bentang lahan baik secara vegetasi maupun secara topografi juga terjadi di DAS Karangmumus Hulu dengan telah beroperasinya perusahaan tambang batubara. Beberapa kegiatan tersebut tentu akan mempunyai pengaruh baik secara langsung maupun tidak langsung terhadap siklus hidrologi mikro di lingkungan sekitar. Perubahan yang sering terjadi adalah pengaruh terhadap laju limpasan permukaan dan erosi lahan. Pengaruh terhadap siklus hidrologi mikro dapat dirasakan saat ini maupun secara akumulatif pada masa yang akan datang.

Tujuan dari penelitian adalah membuat analisis sistem pengendalian banjir, memberikan informasi tentang sistem pengendalian banjir dengan berbagai skenario yang direncanakan.

\section{METODE PENELITIAN}

\section{Waktu dan Lokasi}

Studi dilaksanakan selama 4 bulan pada Sub DAS Karangmumus hulu yang terletak di Kelurahan Sei Siring Kecamatan Samarinda Utara Kota Samarinda, Provinsi Kalimantan Timur.

\section{Lingkup Studi}

Secara garis besar ruang lingkup studi mengenai pelaksanaan penelitian untuk menganalisis sistem pengendalian banjir Sungai Karangmumus Atas (Lempake) ini meliputi :

1. Melakukan survey lapangan secara detail sebagai dasar perencanaan desain secara spesifik dan mendetail mengenai kondisi awal Sungai Karangmumus Atas (Lempake) tersebut

2. Mengidentifikasi faktor-faktor yang menyebabkan banjir

3. Memberikan kontribusi yang nyata dari program pembangunan yang berwawasan lingkungan untuk meminimalkan dampak lingkungan dan sosial yang terjadi. 
JURNAL KACAPURI

JURNAL KEILMUAN TEKNIK SIPIL

Volume 3 Nomor 2 Edisi Desember 2020

\section{HASIL DAN PEMBAHASAN}

\section{Sistem Pengendalian Banjir}

Untuk menangani genangan banjir di kawasan Pampang dan sekitarnya diperlukan data informasi mengenai besaran genangan yang meliputi : luasan, kedalaman/tinggi, durasi dan frekuensi dan tingkat kerugian yang diakibatkan oleh genangan banjir. Agar pelaksanaan penanganan ini dapat maksimal perlu disusun suatu sistem pengendalian banjir dengan mengacu pada parameterparameter tertentu guna menentukan suatu jenis bangunan pengendali banjir.

Sesuai dengan hasil survei dan investigasi bahwa untuk menangani masalah banjir di kawasan Pampang dan sekitarnya perlu dilakukan upaya-upaya untuk pengendaliannya dengan menggunakan pendekatan engineering aspect. Hasil survei tersebut secara spesifik juga memberikan alternatif mengenai sistem atau pola pengendalian banjir tersebut sesuai dengan kondisi karakteristik teknis maupun nonteknis dari DAS tersebut.

Untuk menentukan atau memilih alternatif bangunan yang paling optimal untuk diterapkan di sungai Pampang dan sungai Karangmumus atas maka perlu dimasukkan parameter teknis maupun nonteknis lainnya. Diharapkan dengan kajian tersebut maka pemilihan jenis bangunan yang paling optimal dari segi teknis, fungsi, manfaat dan pembiayaannya dapat diketahui.

\section{Analisis Pengendalian Banjir}

Untuk analisis pengendalian banjir dilakukan berbagai tahapan dalam melakukan perencanaan bangunan pengendali banjir., yaitu melakukan perencanaan bangunan pengendali banjir melalui analisa dan routing banjir menggunakan program HEC RAS. Model Hidrolika disusun untuk mengetahui proses masuknya banjir ke badan sungai dan mengetahui elevasi muka air di sungai dan sekitarnya pada saat terjadinya banjir. Untuk melakukan analisa model hidrolika sungai, dipakai paket program Hec-RAS dari Hydrologic Engineering Center (HEC) dari US Army Corps of Engineers. Paket program ini dimungkinkan untuk menganalisis aliran sungai pada kondisi aliran Unsteady Flow, dan juga memungkinkan dilakukan perhitungan hidrolis profil muka air sungai dengan memperhatikan aliran lateral dan stage hidrograph waduk Lempake sebagai syarat batas.

\section{Simulasi pengendalian banjir}

Untuk mengetahui kondisi banjir di sepanjang alur sungai dilakukan penelusuran banjir lewat palung sungai. Penelusuran banjir dilakukan untuk kondisi saat ini berdasarkan data karakteristik alur sungai dan bantaran banjirnya. Berdasarkan hasil penelusuran diketahui bahwa kapasitas saluran atau sungai yang ada sudah tidak mampu menampung limpasan debit dari daerah tangkapan air yang ada. Mencermati kondisi ini diperlukan suatu desain yang ideal untuk menampung debit yang masuk ke dalam saluran agar dapat mengurangi limpasan dan menurunkan muka air banjir. 
JURNAL KACAPURI

JURNAL KEILMUAN TEKNIK SIPIL

Volume 3 Nomor 2 Edisi Desember 2020

Pada kondisi rencana analisis Hidrolika dilakukan untuk desain kapasitas yang mampu untuk mengalirkan banjir rencana. Perencanaan atau desain penampang sungai meliputi perencanaan dimensi saluran, kemiringan dasar saluran yang nantinya akan menghasilkan desain tinggi muka air. Perencanaan ini dimaksudkan untuk mendapatkan kapasitas optimal yang dapat menampung debit aliran yang masuk ke dalam saluran atau sungai sehingga tidak menyebabkan terjadinya limpasan di sepanjang jalur saluran atau sungai dan juga untuk menurunkan muka air banjir.

\section{Skenario permodelan pengendalian banjir}

Analisis hidrolika dilakukan pada sungai Pampang dengan panjang sungai total hampir 6,5 $\mathrm{Km}$ dilakukan dengan menggunakan debit banjir rerata (Q5) tahun dengan beberapa skenario sebagai berikut :

Plan 00 : Kondisi eksisting yang ada saat ini tanpa melakukan perubahan sistem di dalam daerah aliran sungai.

Plan 01 : Kondisi eksisting Sungai Pampang dengan tambahan Bendali di Sungai Karangmumus Atas

Plan 02 : Kondisi eksisting Sungai Pampang dengan tambahan Bendali Karangmumus Atas dan Bendali Sei Siring.

Plan 03 : Kondisi Normalisasi Sungai Pampang

Plan 04 : Kondisi Eksisting Sungai Pampang dengan tambahan Sudetan atau by pass.

Plan 05 : Kondisi Eksisting Sungai Pampang dengan hidrograf reduksi $40 \%$

Berikut ini adalah disajikan skema Sungai Pampang sesuai dengan beberapa skenario yang telah di atas.

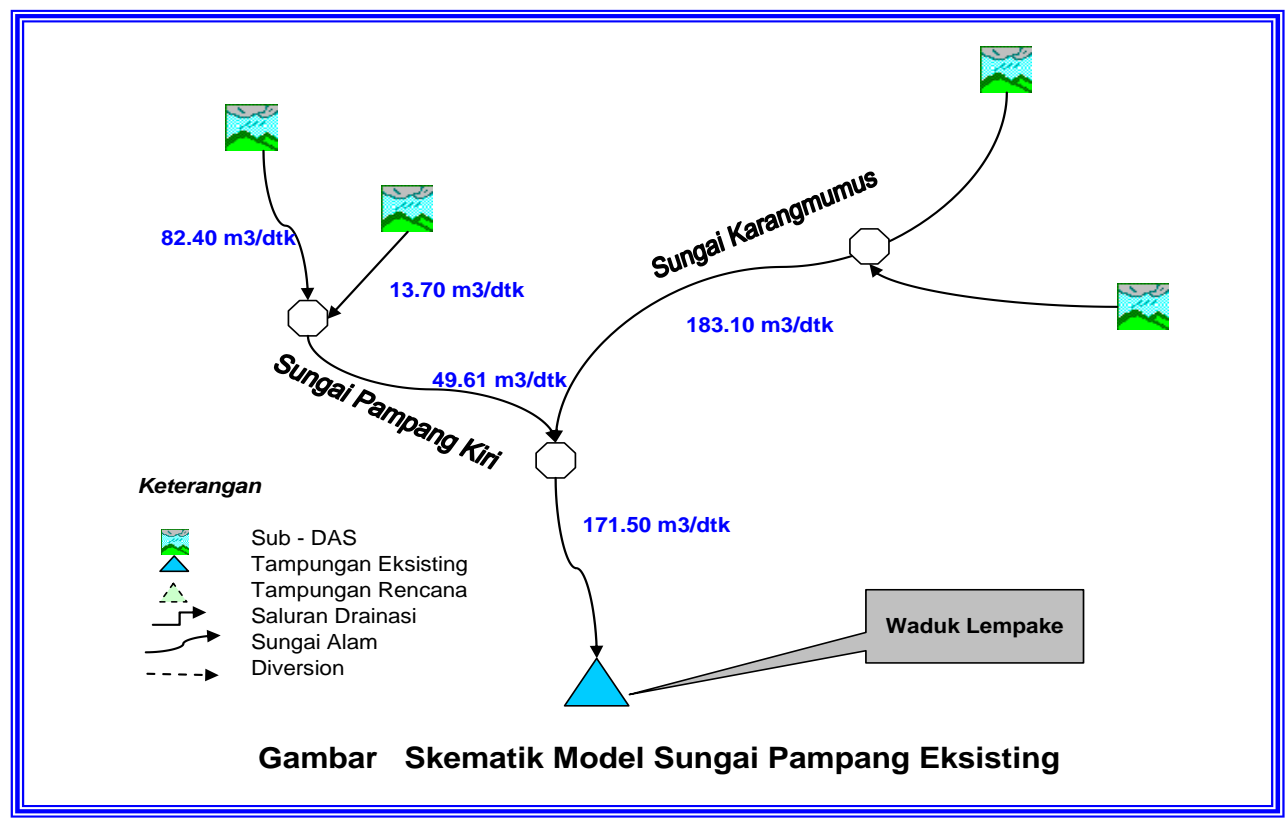

Gambar 1. Skema pada Skenario 01 
JURNAL KACAPURI

JURNAL KEILMUAN TEKNIK SIPIL

Volume 3 Nomor 2 Edisi Desember 2020

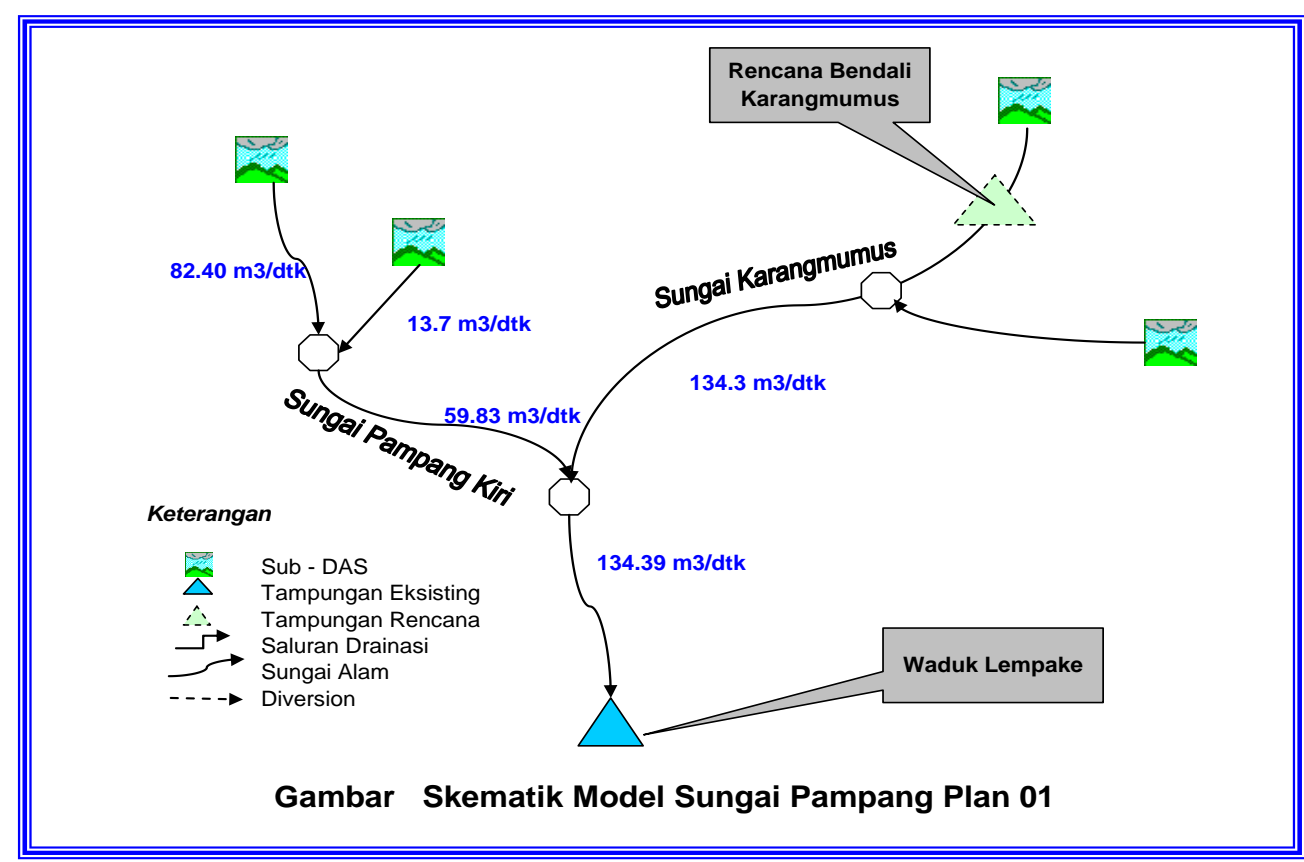

Gambar 2. Skema pada Skenario 02

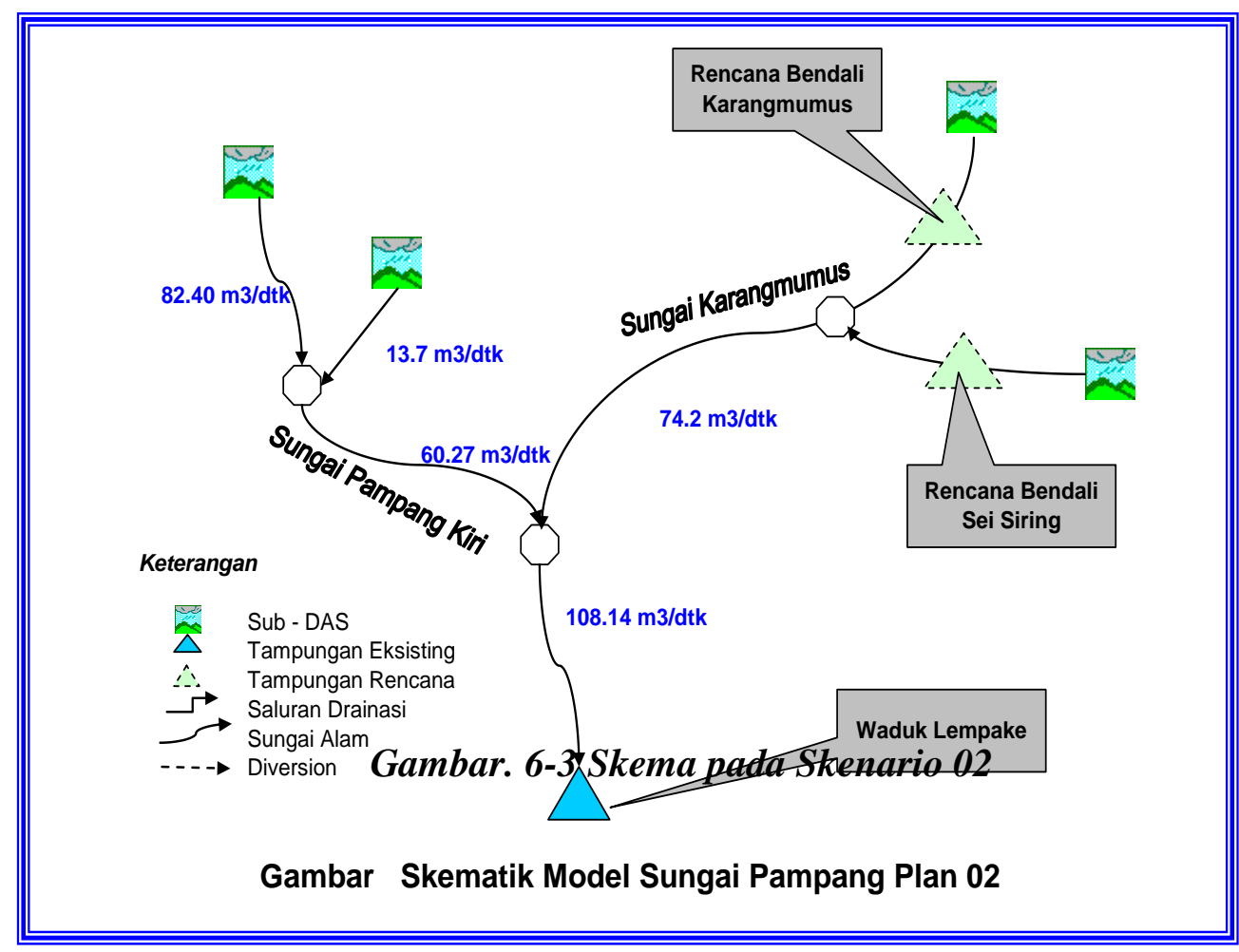

Gambar 3. Skema pada Skenario 03 
JURNAL KACAPURI

JURNAL KEILMUAN TEKNIK SIPIL

Volume 3 Nomor 2 Edisi Desember 2020

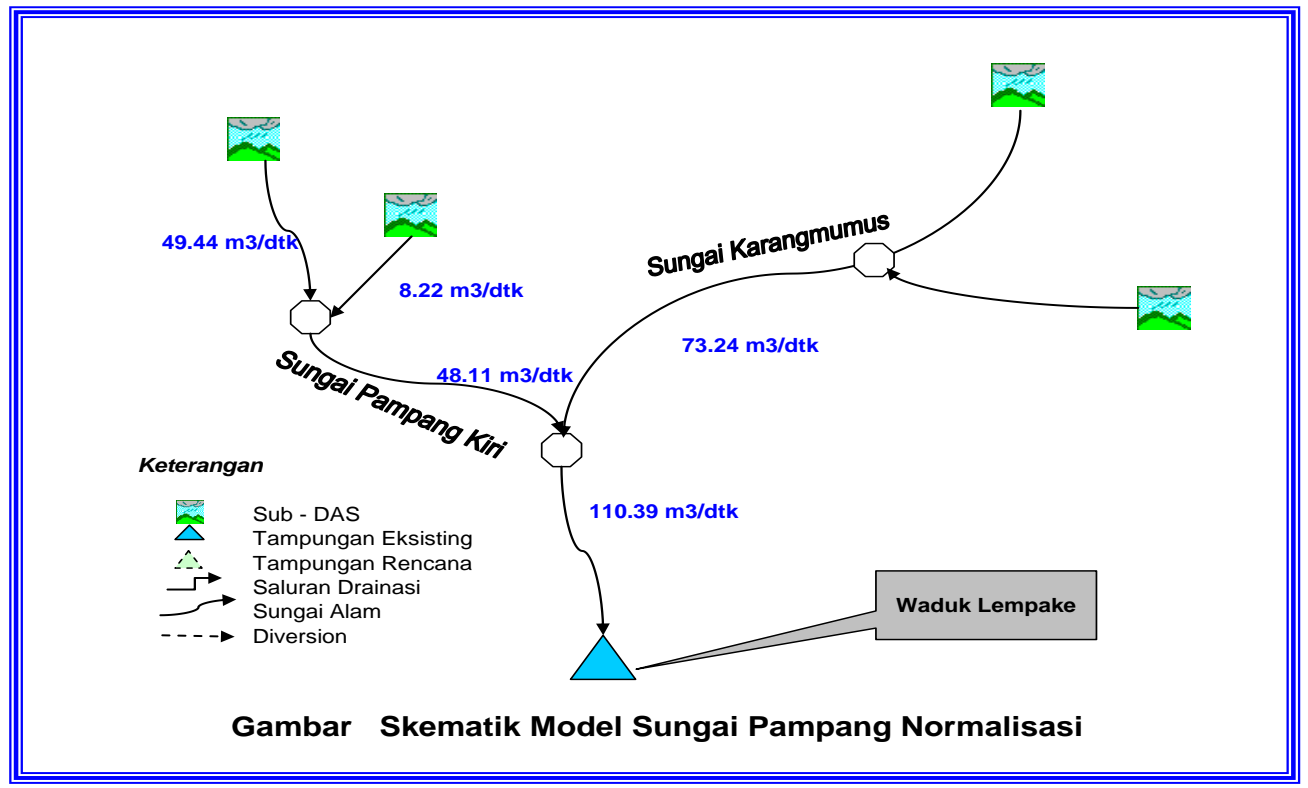

Gambar 4. Skema pada Skenario 04

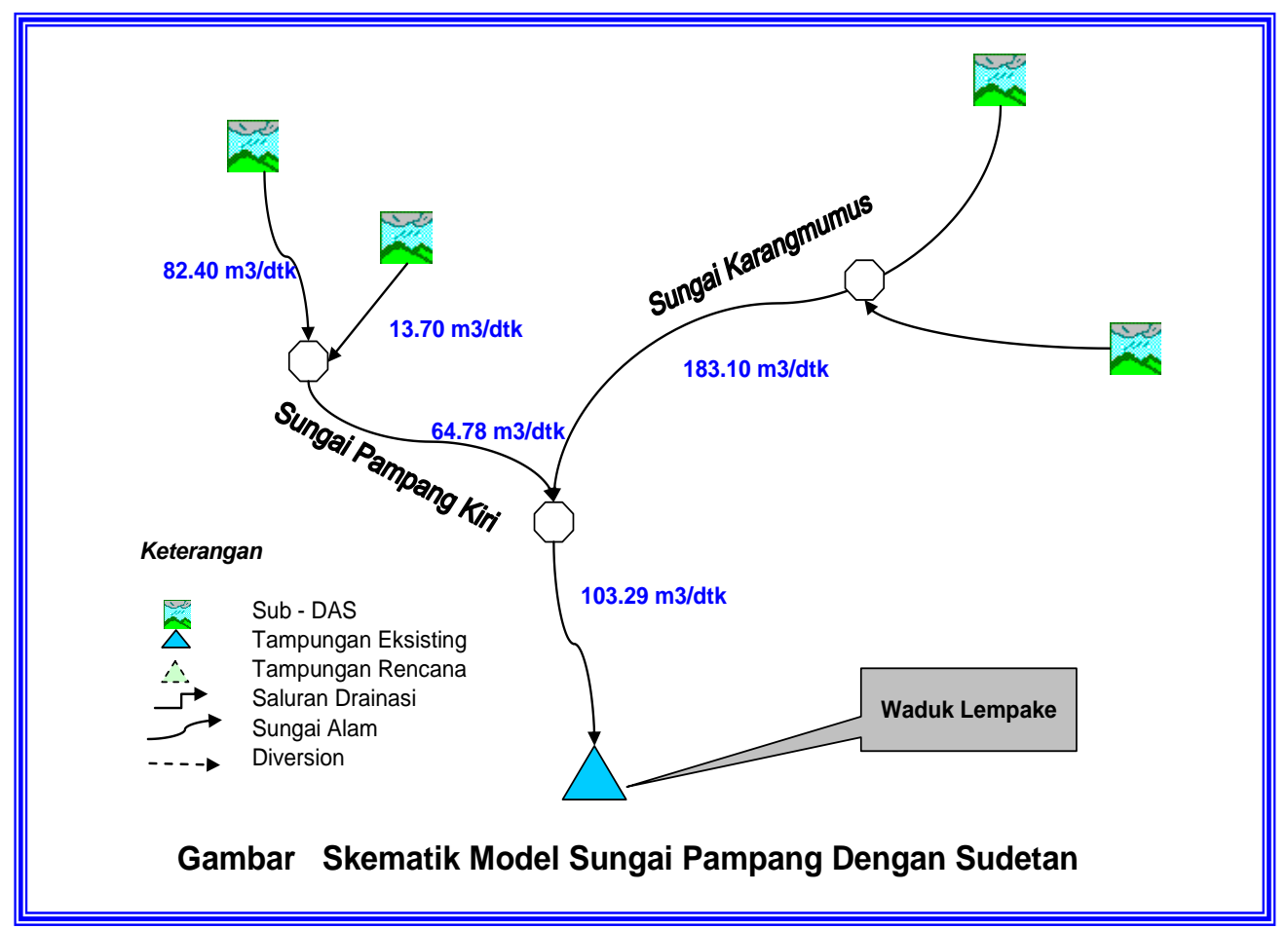

Gambar 5. Skema pada Skenario 05 
JURNAL KACAPURI

JURNAL KEILMUAN TEKNIK SIPIL

Volume 3 Nomor 2 Edisi Desember 2020

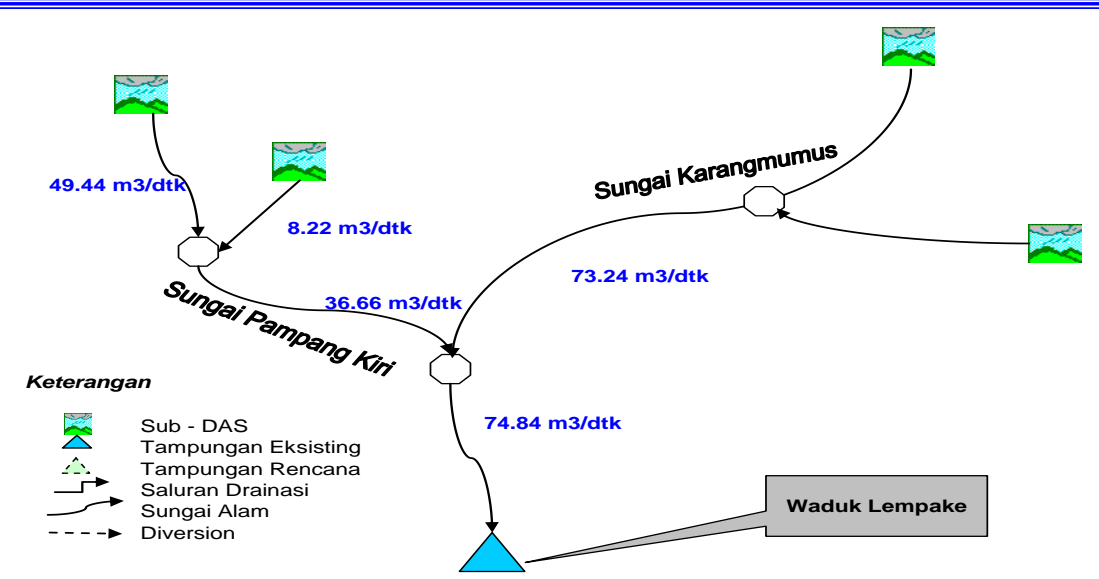

Gambar Skematik Model Sungai Pampang Eksisting Reduksi $40 \%$

Gambar 6. Skema pada Skenario 06

Untuk permodelan hidrolika sungai Pampang dengan program HEC-RAS disajikan pada Gambar 7.

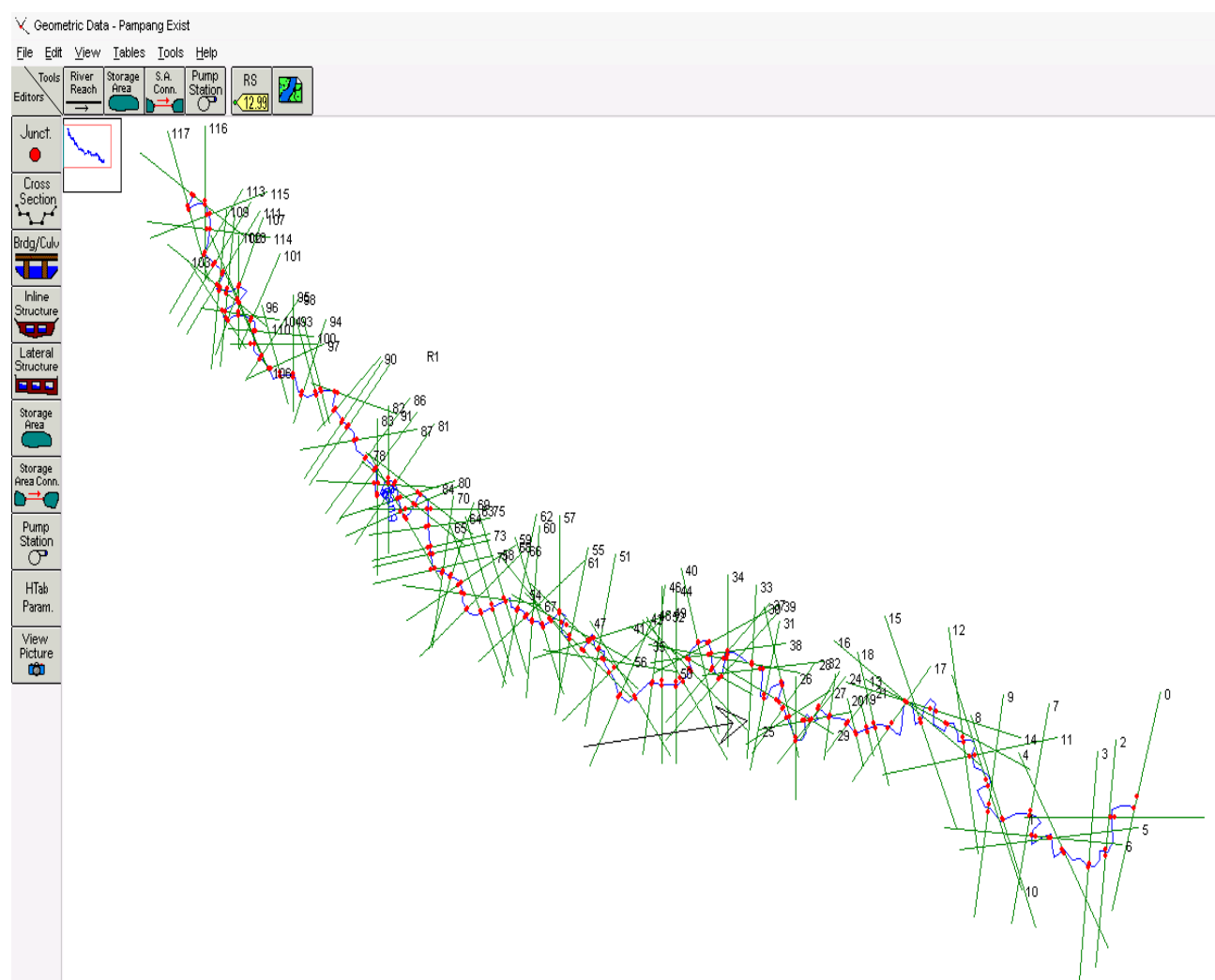

Gambar 7. Model Geometrik Data sungai Pampang pada program HEC RAS

Sungai Pampang akan dikaji dan dievaluasi terhadap beberapa kondisi yang menyesuaikan dengan kondisi pada model hidrologi ditambah dengan kondisi 
JURNAL KACAPURI

JURNAL KEILMUAN TEKNIK SIPIL

Volume 3 Nomor 2 Edisi Desember 2020

Normalisasi Sungai. Sebagai syarat batas hulu adalah keluaran air dari Hulu Sungai Pampang dan Sungai Karangmumus atas pada bagian tengah masuk beberapa anak sungai, sehingga masukan pada model di bagian tengah adalah inflow hidrograf dari beberapa anak sungai tersebut sedangkan pada bagian downstream batas hilirnya berupa stage hidrograph waduk Lempake. Berikut adalah gambar batas batas hidrograph banjir sungai Pampang (Gambar 8 dan 9).

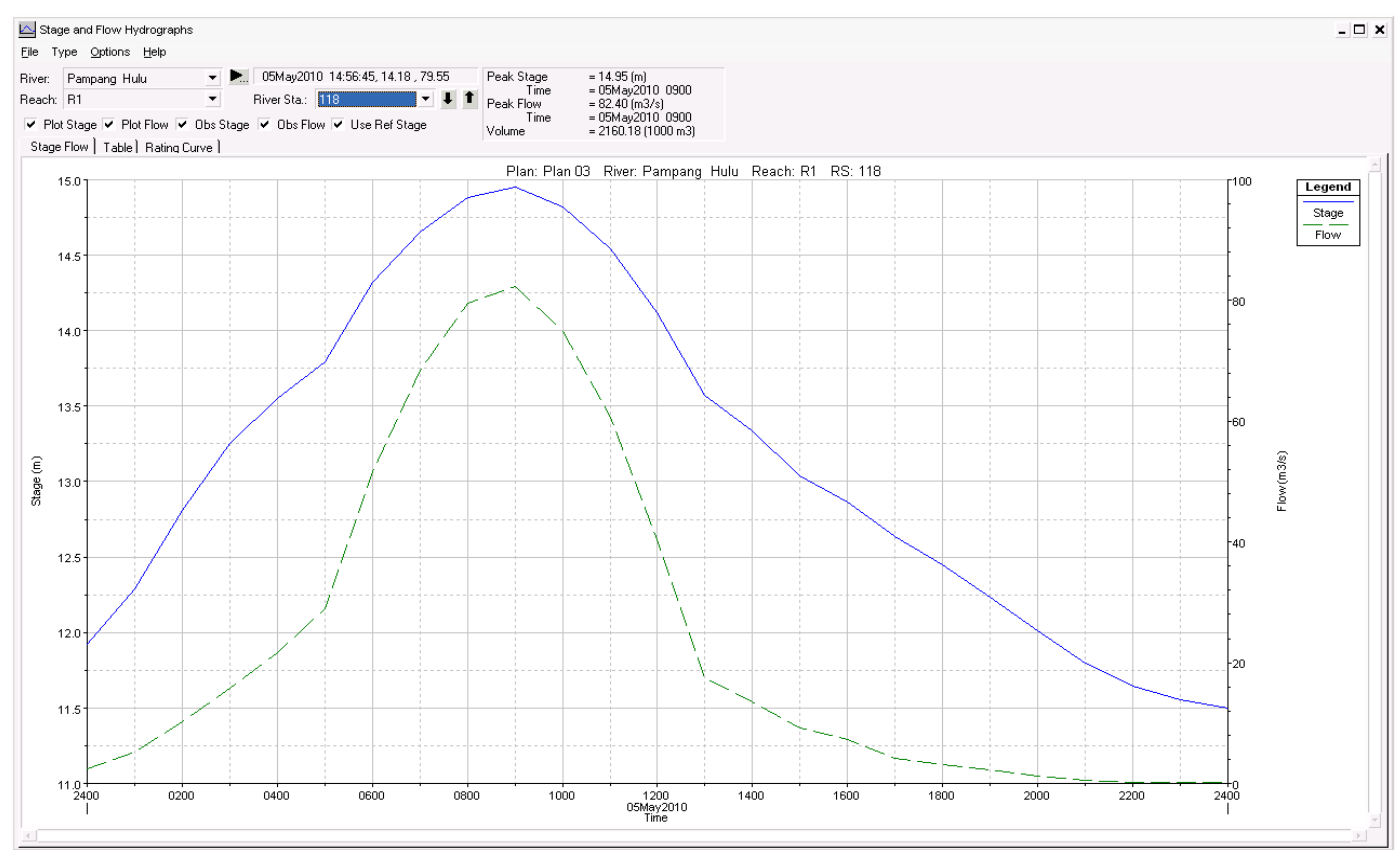

Gambar 8. Hidrograph Banjir Batas Hulu Sungai Pampang

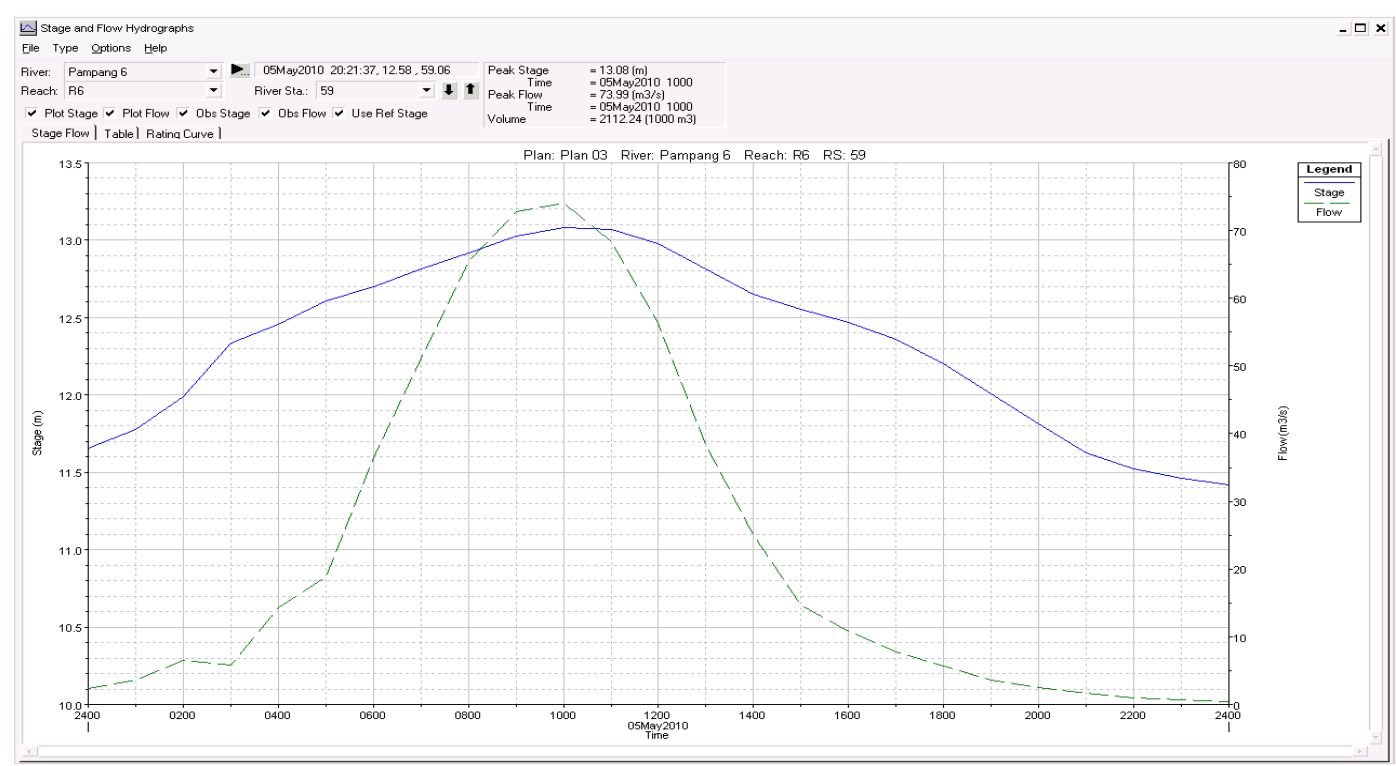

Gambar 9. Hidrograph Banjir Batas Tengah Sungai Pampang 
JURNAL KACAPURI

JURNAL KEILMUAN TEKNIK SIPIL

Volume 3 Nomor 2 Edisi Desember 2020

\section{Keluaran model}

Berdasarkan dari simulasi sistem pengendalian banjir yang dilakukan dengan bantuan paket Program Hec - RAS didapatkan profil muka air banjir di sepanjang alur sungai yang ditinjau. Untuk membandingkan kondisi yang ada saat ini dan kondisi yang direncanalan (sistem pengendalian banjir rencana) secara grafis ditampilkan profil muka air sepanjang alur sungai yang ditinjau. Gambar 10 sampai 15 menunjukkan keluaran model profil muka air dari berbagai skenario.

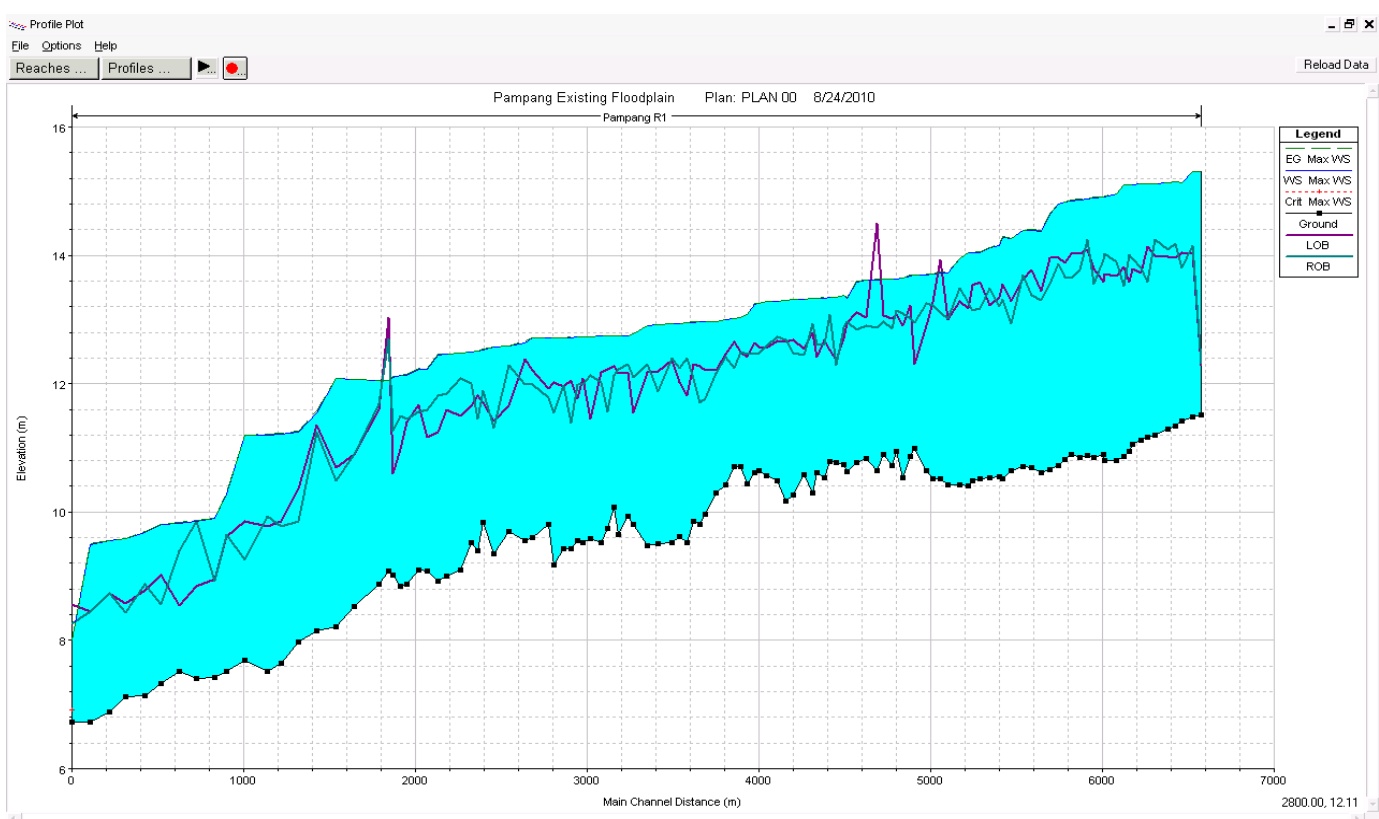

Gambar 10. Profil Muka Air Sungai Pampang Kondisi Plan 02

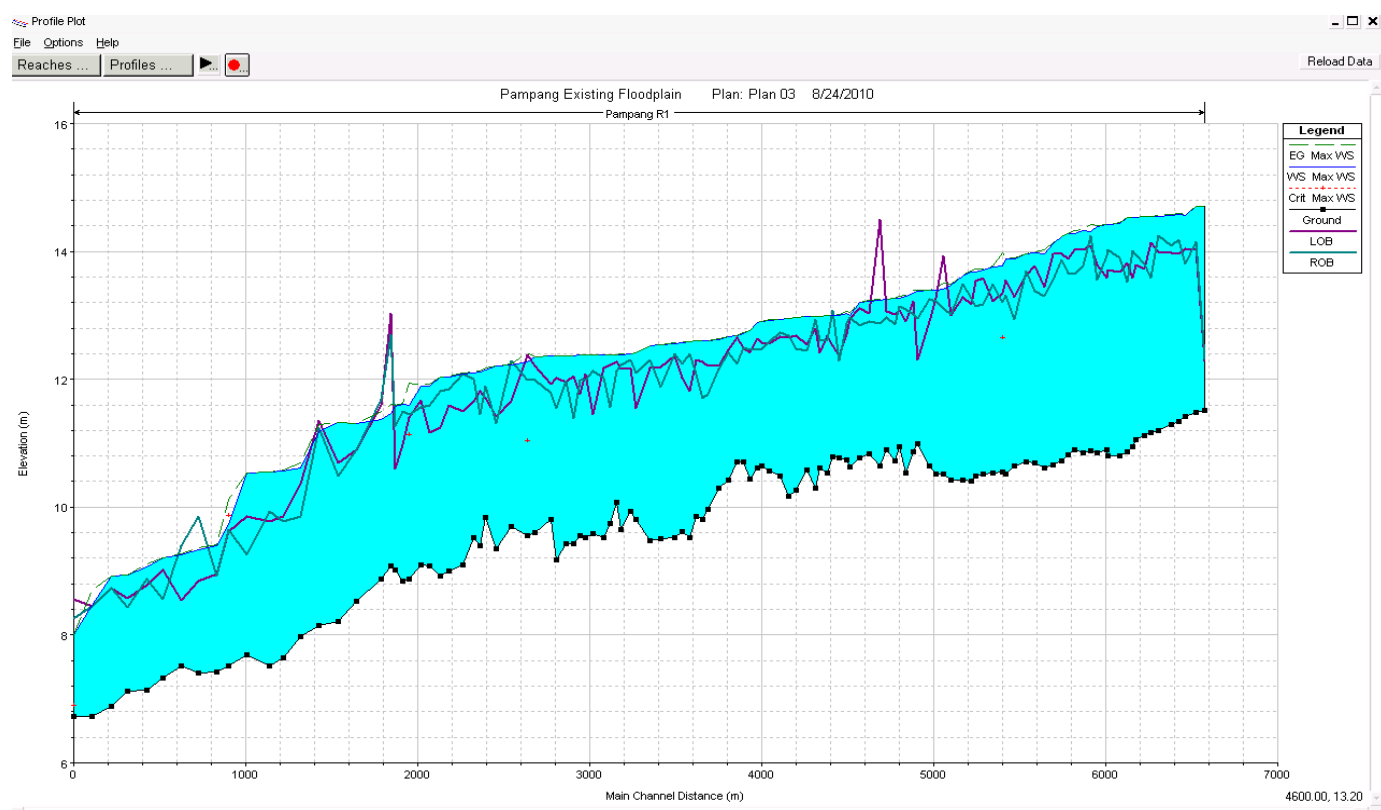

Gambar 11. Profil Muka Air Sungai Pampang Kondisi Plan 03 
JURNAL KACAPURI

JURNAL KEILMUAN TEKNIK SIPIL

Volume 3 Nomor 2 Edisi Desember 2020

\section{Normalisasi Sungai Pampang}

Sungai Pampang adalah anak sungai Karangmumus, bagian hilir sungai adalah Sungai Karangmumus. Dari hasil investigassi lapangan dan analisis perhitungan dalam penelusuran banjir, diperoleh bahwa kapasitas alir sungai Pampang sudah tidak memenuhi syarat untuk menampung debit air. Untuk itu diperlukan suatu desain yang ideal untuk menampung debit air dari hulu agar kapasitas alir yang diperlukan dapat terpenuhi, sehingga dapat menurunkan muka air banjir/mengurangi limpasan air dari sungai. Selain itu diperlukan penataan kawasan sempadan sungai yang diharuskan terbebas dari pemukiman, sehingga laju aliran air tidak terganggu. Dalam hal ini dikemukakan suatu desain normalisasi sungai, dimana telah dianalisis secara hidrolik untuk mendapatkan desain ideal suatu penampang sungai yang dibutuhkan dalam menurunkan muka air banjir. Berikut adalah data teknis normalisasi sungai Pampang hasil perhitungan dan simulasi.

PERHITUNGAN KAPASTAS DESAIN SUNGAI PAMPANG ( DOWN STREAM )

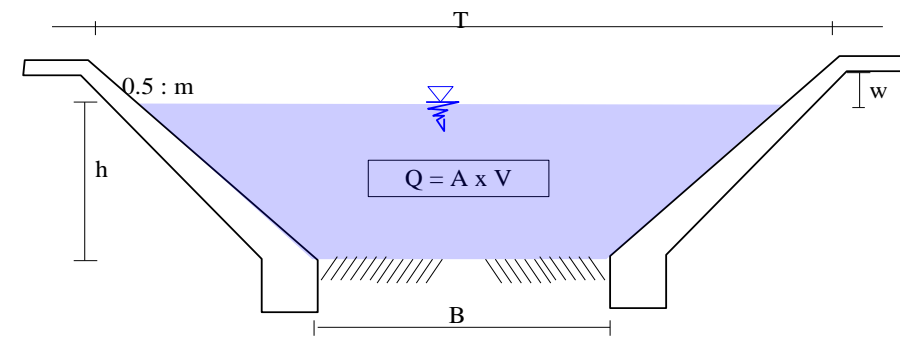

SKETSA DIMENSI SUNGAI

Perhitungan Luas Penampang Saluran

Lebar Dasar Saluran (B)

Keminingan Talud $(m)$

Tinggi Jagaan ( w )

Kedalaman Air (h)

Kedalaman Saluran $(\mathrm{H})$

Lebar Atas Saluran ( T)

Perhitungan Kapasitas Debit Saluran ( Hidrolika )

Debit Banjir Rencana $\left(Q_{5}\right)$

Keminingan Dasar Renc. (S)

Kekasaran Manning ( $\mathrm{n}$ )

Luas Penampang Basah (A)

Keliling Basah Saluran (P)

Jani-jari Hid rolik ( R)

Kecepatan Aliran

Kapasitas Alir Sal. (Q)

\section{$=$}

$=$

$=$

$=$

$=$

$$
=
$$

\section{$=$}

$=$

$=$

$$
\begin{array}{lll}
12 \mathrm{~m} & & \\
0.50 & & \\
0.5 \mathrm{~m} & & \\
4.000 \mathrm{~m} & & \\
4.500 \mathrm{~m} & = & \mathrm{w}+\mathrm{h} \\
16.000 \mathrm{~m} & = & B+2 \times \mathrm{m} \times \mathrm{H}
\end{array}
$$

$110.00 \mathrm{~m}^{3} / \mathrm{dt}$

0.00089

0.025

$B \times h+2 \times 0,5 \times(1+m) \times h$

$56.000 \mathrm{~m}^{2}$

$B+2 \times h\left(1+m^{2}\right)^{0,5}$

$20.944 \mathrm{~m}$

A / P

$2.674 \mathrm{~m}$

$1 / \mathrm{n} \times \mathrm{R}^{2 / 3} \times \mathrm{S}^{0,5}$

$\mathrm{A} \times \mathrm{V}$

$2.299 \mathrm{~m} / \mathrm{dt}$

$128.756 \mathrm{~m}^{3} / \mathrm{dt}$

Berikut ini disajikan profil muka air hasil routing sungai Pampang pada kondisi eksisting dan kondisi setelah normalisasi. 
JURNAL KACAPURI

JURNAL KEILMUAN TEKNIK SIPIL

Volume 3 Nomor 2 Edisi Desember 2020

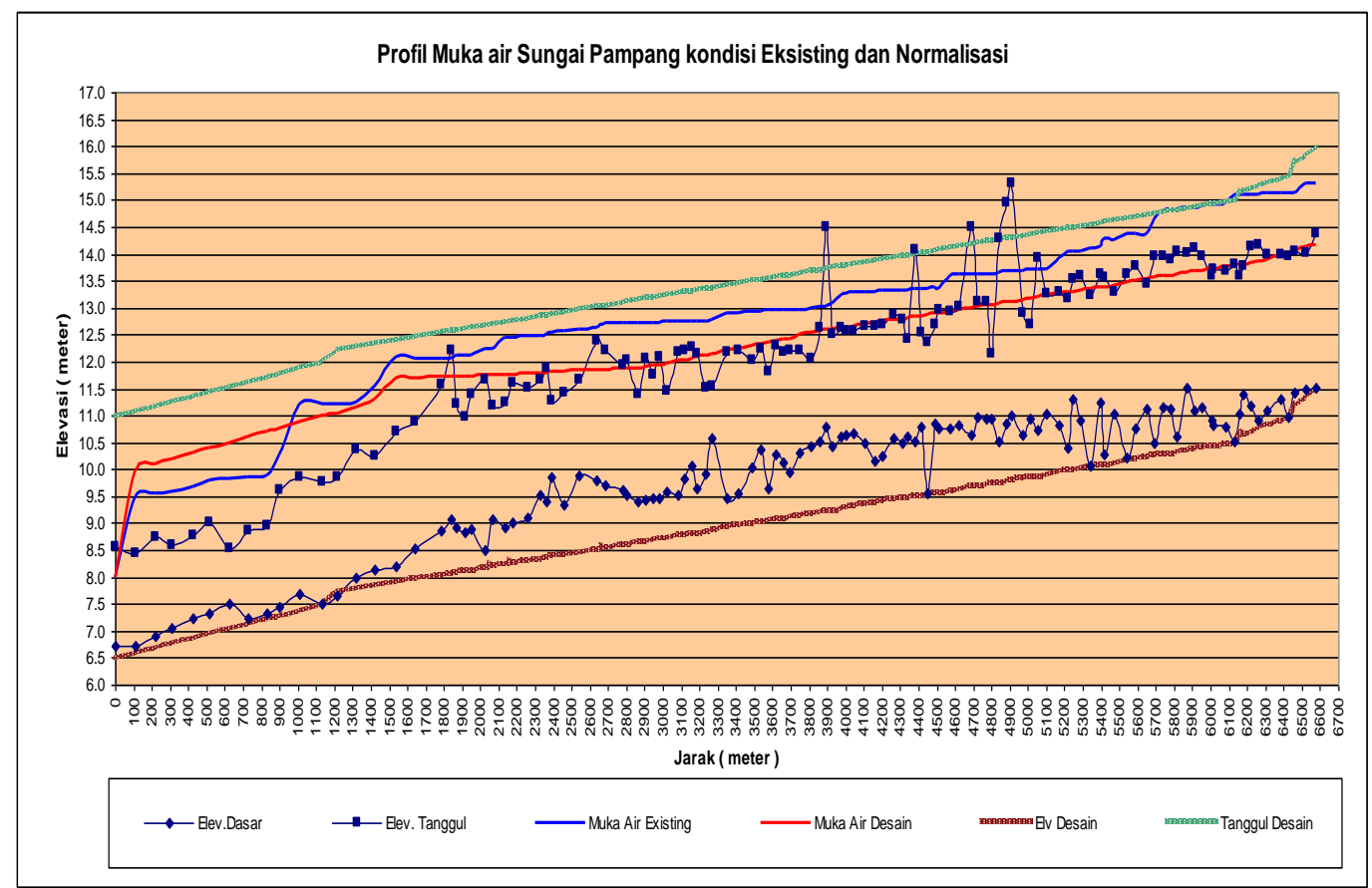

Gambar 12. Profil muka air sungai Pampang kondisi Eksisting dan Normalisasi

\section{Sudetan Sungai Pampang}

Banjir yang terjadi di bagian tengah (middle stream) Sungai Pampang adalah akibat adanya antrian air di bagian bagian sungai yang padat dengan meandermeander limpasan air ke permukaan. Sudetan Sungai Pampang direncanakan untuk memotong jalur antrian air yang terjadi di bagian middle stream Sungai Pampang yang mempunyai banyak meander, hal ini dimaksudkan untuk mengurangi debit air yang terkonsentrasi di lokasi-lokasi meander sungai Pampang. Sudetan Sungai Pampang ini direncanakan dengan data teknis sebagai berikut :

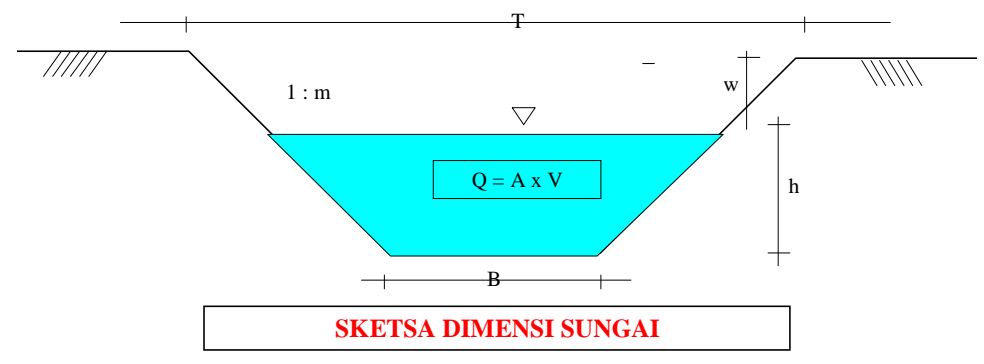

Perhitungan Luas Penarrıarıy saluraı

Lebar Dasar Saluran (B)

Keminingan Talud $(\mathrm{m})$

Ting i Jagaan ( w )

Kedalaman Air (h)

Kedalaman Saluran(H)

Lebar Atas Saluran ( T)

Perhitungan Kapasitas Debit Saluran (Hidrolika )

Debit Banjir Rencana $\left(Q_{5}\right)$

Kemingan Dasar Renc. (S)

Kekasaran Manning ( $n$ )

Luas Penampang Basah ( A )

Keliling Basah Saluran (P)

Jari-jari Hidrolik ( $R$ )

Kecepatan Aliran

Kapasitas Alir Sal. (Q)

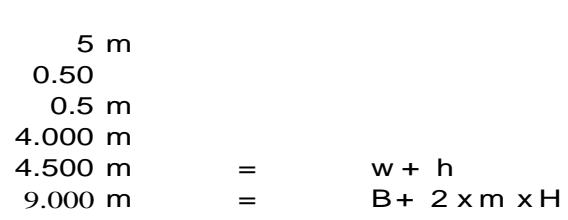

$$
\begin{gathered}
85.00 \mathrm{~m}^{3} / \mathrm{dt} \\
0.002985 \\
0.025 \\
\mathrm{~B} \times \mathrm{h}+2 \times 0,5 \times(1+\mathrm{m}) \times \mathrm{h} \\
28.000 \mathrm{~m}^{2} \\
\mathrm{~B}+2 \times \mathrm{h}\left(1+\mathrm{m}^{2}\right)^{0,5} \\
13.944 \mathrm{~m} \\
\mathrm{~A} / \mathrm{P} \\
2.008 \mathrm{~m} \\
1 / \mathrm{n} \times \mathrm{R}^{2 / 3} \times \mathrm{S}^{0,5} \\
\mathbf{3 . 4 7 8} \mathrm{m} / \mathrm{dt} \\
\mathrm{A} \times \mathrm{V} \\
97.395 \mathrm{~m}^{3} / \mathrm{dt}
\end{gathered}
$$


JURNAL KACAPURI

JURNAL KEILMUAN TEKNIK SIPIL

Volume 3 Nomor 2 Edisi Desember 2020

Selanjutnya gambar 13 di bawah ini adalah profil muka air sungai Pampang hasil analisis perhitungan dan simulasi.

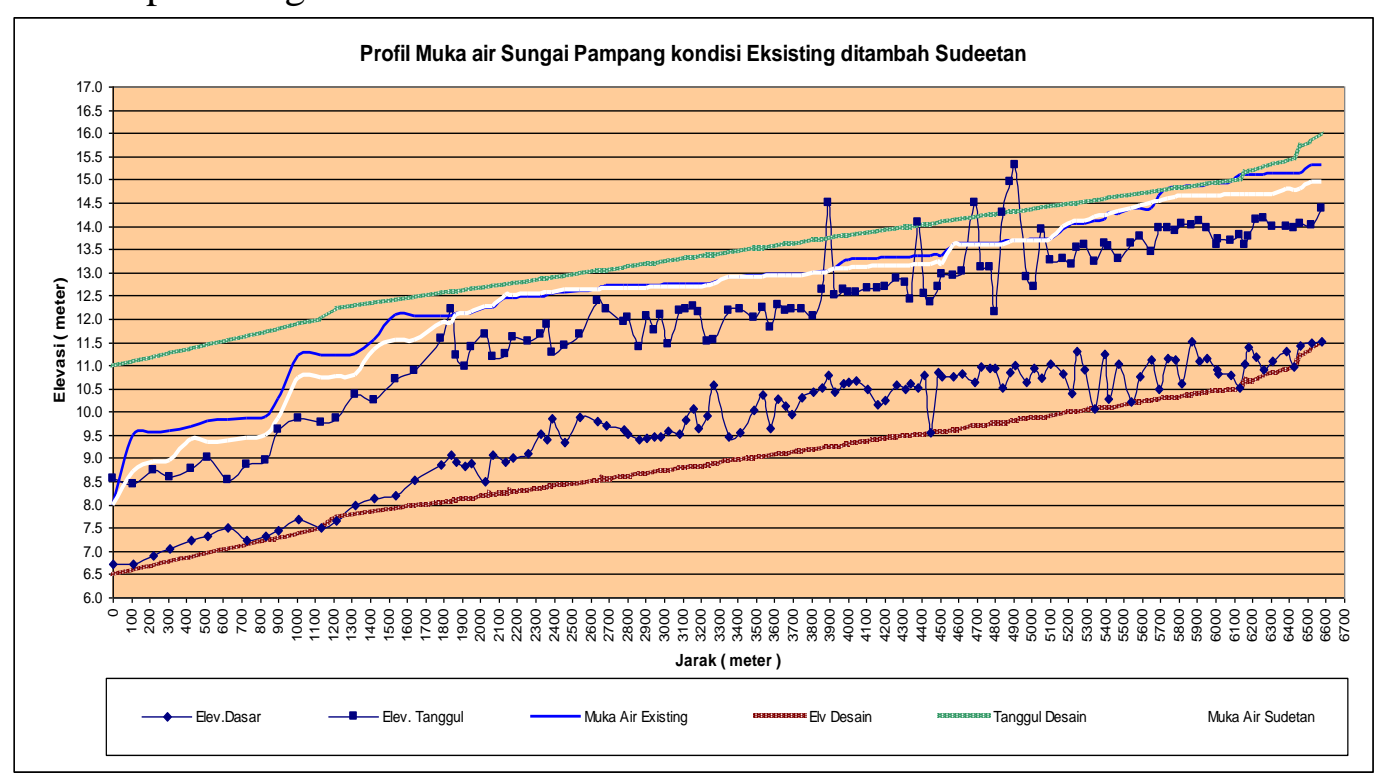

Gambar 13. Profil muka air sungai Pampang kondisi Eksisting dan Sudetan

Dengan menganalisis hasil model hidrolika beberapa pernyataan yaitu sebagai berikut :

1. Dari hasil eksekusi penelusuran banjir lewat alur sungai dapat dicermati bahwa untuk menampung debit banjir dari daerah hulu perlu dilakukan normalisasi, sehingga limpasan air permukaan dapat tertampung pada alur sungai.

2. Untuk membantu mereduksi limpasan permukaan di bagian sungai yang terdapat meander meander maka dilakukan penyudetan atau pembuatan shortcut atau bypass sehingga tidak terjadi antrian alir yang mengakibatkan limpasan.

3. Untuk membantu mereduksi limpasan permukaan dari daerah hulu, dimana saat ini banyak di kembangkan pemukiman baru maka tampungan dalam skala kecil di pemukiman diperlukan seperti sumur resapan. Dengan pembuatan sumur resapan maka akan sangat membantu mengurangi limpasan ditingkat lokal pemukiman penduduk, sebelum limpasan masuk ke saluran drainase.

\section{KESIMPULAN DAN SARAN}

\section{Kesimpulan}

Berdasarkan hasil analisis dan pembahasan dapat diambil kesimpulan yaitu sebagai berikut :

1. Penyebab permasalahan banjir secara alam yang paling dominan adalah kondisi topografi daerah rawan banjir yang relatif rendah dan datar dan merupakan daerah konsentrasi limpasan permukaan dari daerah tangkapan air sungai Karang Mumus dan Sungai Pampang.

2. Sistem drainase masih menghadapi permasalahan baik itu secara sistem, 
sarana fisik/struktur maupun kendala yang bersifat non struktur.

3. Berdasarkan kajian potensi pengendali banjir, sistem pengendalian banjir Sungai Karang Mumus Atas dapat dilakukan secara struktural maupun nonstruktural.

4. Ada 5 buah skenario sistem pengendalian banjir yang ada. Dalam skenario tersebut dilakukan kombinasi antara kondisi eksisting dengan beberapa bendali dan sudetan. Sementara juga dilakukan skenario dengan hanya melakukan normalisasi sungai Pampang.

\section{Saran}

Berdasarkan hasil penelitian ada beberapa yang dapat dikemukakan yaitu antara lain :

1. Berdasarkan kondisi ini maka untuk mengurangi dampak banjir di Lempake Atas program pengendalian banjir sedapat mungkin segera diimplementasikan.

2. Program pengendalian banjir yang telah disusun harus dilakukan sosialisasi, baik itu kepada masyarakat maupun instansi terkait. Selanjutnya pihak pemerintah melalui instansi terkait harus mempunyai komitmen dan konsisten dalam pelaksanaan program yang telah direncanakan tersebut.

3. Dari berbagai skenario model sistem pengendalian banjir yang telah dikaji, kegiatan normalisasi sungai Pampang merupakan kegiatan prioritas, sedangkan untuk menambah tingkat reduksi banjir perlu dikombinasi dengan bangunan pengendali (Bendali Pampang dan Bendali Karangmumus). Khusus untuk mengurangi beban banjir akibat limpasan lokal di pemukiman diperlukan perbaikan sistem drainase lingkungan.

4. Dilakukan revitalisasi fungsi 2 rawa besar yaitu di sub DAS Karangmumus dan sub DAS Pampang Kanan., sehingga beban banjir maupun beban sedimen di waduk Lempake dapat dikurangi.

5. Berdasar perkembangan pemukiman di daerah hulu dengan cara melakukan pembukaan lahan di daerah perbukitan maka perlu dilakukan pengendalian laju sedimentasi seperti pembuatan cek dam dan membuat sumur resapan atau kolam-kolam retensi lokal di pemukiman tersebut.

6. Kearifan lokal masyarakat Lempake Atas dalam hal pengembangan pemukiman dengan rumah panggung di daerah rawan banjir perlu untuk dilestarikan.

7. Pengendalian secara struktural tidak akan memberikan hasil yang nyata dan berkelanjutan tanpa didukung pengendalian banjir dengan cara non struktural seperti kegiatan konservasi DAS, penegakan peraturan/hukum serta partisipasi/peranserta masyarakat. 


\section{DAFTAR PUSTAKA}

1. Asdak, C. 1995. Hidrologi dan Pengolahan Daerah Aliran Sungai. Gajah Mada University Press, Yogyakarta.

2. Hadisusanto, N. 2011. Aplikasi Hidrologi. Jogja Media Utama, Malang.

3. Ikhsan, M. 2005. Perencanaan Sistem Drainase pada Sungai Buntung Kabupaten Sidoarjo. Jurnal Neutron Vol. 5 No.1 Februari 2005.

4. Indarto. 2010. Hidrologi Dasar Teori dan Model Hidrologi. Bumi Aksara, Jakarta.

5. Kodoatie. 2008. Pengelolaan Sumber Daya Air Terpadu. Edisi Kedua. Andi Offset, Yogyakarta.

6. Riman, 2012. Evaluasi Kapasitas Tampung Sungai di Daerah Aliran Sungai Dalam Upaya Pengendalian Daya Rusak. Widya Teknik Vol 20 No.2 ISSBN 1411-0660:49-55.

7. Soewarno. 1995. Hidrologi Aplikasi Metode Statistik untuk Analisis Data. Jilid 2, Nova, Bandung.

8. Sosrodarsono, S. dan M. Tominaga. 1994. Perbaikan dan Pengaturan Sungai. Pradnya Paramita, Jakarta.

9. Suripin. 2004. Sistem Drainase Perkotaan yang Berkelanjutan. Andi Offset, Yogyakarta.

10. Triatmodjo, B. 2010. Hidrologi Terapan. Beta Offset Yogyakarta. 